\title{
Association of the angiopoietin-like protein 8 rs2278426 polymorphism and several environmental factors with serum lipid levels
}

\author{
TAO GUO ${ }^{1}$, RUI-XING YIN ${ }^{1}$, JIAN WU ${ }^{1}$, QUAN-ZHEN LIN ${ }^{1}$, GUANG-YUAN SHI ${ }^{1}$, \\ SHAO-WEN SHEN ${ }^{1}$, JIA-QI SUN ${ }^{1}$, HUI LI $^{2}$, WEI-XIONG LIN ${ }^{3}$ and DE-ZHAI YANG ${ }^{3}$ \\ ${ }^{1}$ Department of Cardiology, Institute of Cardiovascular Diseases, The First Affiliated Hospital, Guangxi Medical University; \\ ${ }^{2}$ Clinical Laboratory of the Affiliated Cancer Hospital, Guangxi Medical University; ${ }^{3}$ Department of Molecular Biology, \\ Medical Scientific Research Center, Guangxi Medical University, Nanning, Guangxi 530021, P.R. China
}

Received February 6, 2014; Accepted April 10, 2015

DOI: $10.3892 / \mathrm{mmr} .2015 .3825$

\begin{abstract}
The present study was performed to examine the association of the angiopoietin-like protein 8 (ANGPTL8) rs2278426 single nucleotide polymorphism (SNP) and several environmental factors with serum lipid profiles in the Mulao and Han populations. A total of 879 individuals of the Mulao ethnic group and 865 individuals of the Han Chinese ethnic group were included. The serum apolipoprotein (Apo) B level was higher, however the serum ApoA1 level was lower in the Mulao individuals than in the Han individuals $(\mathrm{P}<0.05$ and $\mathrm{P}<0.001$, respectively). The genotypic and allelic frequencies, and the association with the ANGPTL8 rs2278426 SNP were different between the Mulao and Han populations. The frequency of the A allele was $17.80 \%$ in Han individuals and $23.04 \%$ in Mulao individuals $(\mathrm{P}<0.001)$. The frequencies of GG, GA and AA genotypes were 68.79, 26.82 and $4.39 \%$ in the Han population, and $60.64,32.65$ and $6.71 \%$ in the Mulao population $(\mathrm{P}<0.005)$, respectively. A significant association between the SNP and serum lipid traits was only detected in Han females and not in Han males or in the Mulao population. The subjects with GA/AA genotypes had lower low-density lipoprotein cholesterol (LDL-C) and ApoB levels, and higher ApoA1 levels with a higher ApoA1/ApoB ratio than the subjects with the GG genotype in the Han population. Subgroup analyses revealed that the subjects with the GA/AA genotype had lower levels of total cholesterol, LDL-C and ApoB, and a higher ApoA1/ApoB ratio than the subjects with the GG genotype in Han females $(\mathrm{P}<0.05-\mathrm{P}<0.001)$. Serum
\end{abstract}

Correspondence to: Professor Rui-Xing Yin, Department of Cardiology, Institute of Cardiovascular Diseases, The First Affiliated Hospital, Guangxi Medical University, 22 Shuangyong Road, Nanning, Guangxi 530021, P.R. China

E-mail: yinruixing@163.com

Key words: lipids, apolipoproteins, angiopoietin-like protein 8, single nucleotide polymorphism, environmental factors lipid parameters were also associated with several environmental factors, including dietary patterns, lifestyle, obesity, physical inactivity and hypertension, in the two ethnic groups $(\mathrm{P}<0.05-0.001)$. These findings suggest that there may be an ethnic- and gender-specific association of the rs2278426 SNP and serum lipid parameters.

\section{Introduction}

It is well-established that mortality and morbidity occurring as a result of coronary artery disease (CAD) are a critical public health concern worldwide. Traditional CAD risk factors do not fully predict future CAD events $(1,2)$ and adding modern biomarkers to the standard risk factors has, thus far, only proven to minimally improve individual risk prediction $(3,4)$ thus underlining the requirement to identify novel biomarkers (5). Dyslipidemia, abnormal quantities of lipids in the blood, may be used as a biomarker indicating the susceptibility of an individual to CAD $(6,7)$. Plasma total cholesterol (TC) (8), triglyceride (TG) (9), low-density lipoprotein cholesterol (LDL-C) (10), apolipoprotein (Apo) B (11), high-density lipoprotein cholesterol (HDL-C) (12), ApoA1 and the ApoA1/ApoB ratio (13) are traditionally monitored as predictors of dyslipidemia and also the main target for therapeutic intervention, by regulating blood lipid control (14). Dyslipidemia is well-recognized as a complex trait caused by multiple environmental and genetic factors $(14,15)$, and their interactions $(16,17)$. In twin and familial studies, $40-60 \%$ of the inter-individual variation in plasma lipid phenotypes was explained by heritable factors, such as single nucleotide polymorphisms (SNPs) (18-20).

Angiopoietin-like protein (ANGPTL) has a major role in trafficking and lipid metabolism. ANGPTL8, an ANGPTL family member, is located on chromosome 19 open reading frame 80 (c19orf80) in the corresponding intron of DOCK6. ANGPTL8 is expressed in the liver and adipose tissue, and circulates in the plasma of humans (21). A previous study (22) demonstrated that ANGPTL8 has an important role in lipoprotein metabolism through a functional interaction with ANGPTL3. Co-expression of ANGPTL8 with ANGPTL3 
markedly increased plasma TG levels. Expression of ANGPTL8 was reduced by fasting in humans, while overexpression of ANGPTL8 resulted in hypertriglyceridemia (23). However, the variant in the ANGPTL8 gene has similar effects to complete $A N G P T L 3$ deficiency, which is associated with low plasma levels of LDL-C, HDL-C and TG. Inhibition of ANGPTL8 may be able to provide a novel therapeutic strategy for reducing plasma lipoprotein levels (24). Recently, a common SNP adjacent to the ANGPTL8 locus, termed rs2278426, was identified as an SNP potentially affecting lipoprotein metabolism. The variant of the allele at this SNP was found to be associated with lower plasma LDL-C, HDL-C and TG levels resulting in a significantly reduced risk of CAD in humans (24). However, the effect of this SNP on serum lipid levels is not functionally validated and the mechanism for its action remains to be elucidated. Furthermore, the reproducibility of this association has not been detected in a Chinese population thus far.

China has been a multi-ethnic country since Ancient times (25). Among the 56 ethnic groups present in China, the Han ethnic group has the largest population. The Mulao ethnic group, also known as Mulam, is one of the 55 minorities with a population of 207,352 according to the fifth national census statistics of China in 2000. Of this population, $90 \%$ live in the Luocheng Mulao Autonomous County in the Guangxi Zhuang Autonomous Region. The history of this minority can be traced back to the Jin Dynasty (265-420 AD) (26). One previous study has demonstrated that the genetic association between Mulao ethnicity and other minorities in Guangxi was markedly closer than that between the Mulao and Han or Uighur ethnicity (27). In several previous studies, our group have revealed a significant association between several SNPs (28-31) and serum lipid levels in the Mulao population. To the best of our knowledge, the association between the rs2278426 SNP and serum lipid levels has not been previously examined in the Chinese population. Therefore, the aim of the present study was to assess the association of ANGPTL8 rs2278426 SNP and several environmental factors with serum lipid phenotypes in the Mulao and Han populations.

\section{Materials and methods}

Study population. A total of 879 subjects of Mulao ethnicity who reside in Luocheng Mulao Autonomous County (Guangxi Zhuang Autonomous Region, China) comprising 407 males (46.30\%) and 472 females (53.70\%) and 865 participants of Han Chinese ethnicity residing in the same location, including 425 males $(49.13 \%)$ and 440 females (50.87\%) were randomly selected from our previous stratified randomized samples. The age range was between 15 and 80 years. The mean age of the Mulao participants was $52.69 \pm 14.99$ years, whereas that of the Han subjects was $52.29 \pm 14.26$ years. All participants were essentially healthy rural agricultural workers, with no evidence of disease associated with atherosclerosis, CAD or diabetes. Any participant who had a history of taking medication known to affect serum lipid levels (lipid-lowering drugs, including statins or fibrates, $\beta$-blockers, diuretics or hormones) was excluded from the study prior to the blood sample being obtained. The study design was approved by the Ethics Committee of the First Affiliated Hospital, Guangxi Medical
University (Nanning, China). Informed consent was obtained from all participants.

Epidemiological survey. The survey was conducted using internationally standardized methods, following a previously described protocol (32). Information on demographics, socioeconomic status and lifestyle factors was collected with standardized questionnaires. Alcohol consumption was quantified as the number of liangs ( $\sim 50 \mathrm{~g})$ of rice wine, corn wine, rum, beer or liquor consumed during the preceding 12 months. Alcohol consumption was categorized into groups of grams of alcohol consumed per day: 0 (nondrinker), $\leq 25$ and $>25$. Cigarette smoking status was categorized into groups of cigarettes per day: 0 (non-smoker), $\leq 20$ and $>20$. At the physical examination, several parameters, including height, weight and waist circumference were measured. Sitting blood pressure was measured three times with the use of a mercury sphygmomanometer (Jiangsu Yuyue Medical Equipment \& Supply Co., Ltd., Danyang, China) after at least 5 min of rest and the average of the three measurements was used to indicate blood pressure. Systolic blood pressure was determined by the first Korotkoff sound and diastolic blood pressure was determined by the fifth Korotkoff sound. Body weight, to the nearest $50 \mathrm{~g}$, was measured with a portable balance scale. Height was measured, to the nearest $0.5 \mathrm{~cm}$, using a stadiometer (Shanghai Sangon Biological Engineering Technology \& Services Co., Shanghai, China). From these two measurements, body mass index (BMI, $\left.\mathrm{kg} / \mathrm{m}^{2}\right)$ was calculated. Waist circumference was measured with a non-stretchable measuring tape.

Biochemical measurements. Venous blood samples of $5 \mathrm{ml}$ were drawn after at least $12 \mathrm{~h}$ of fasting. A total of $2 \mathrm{ml}$ of the sample was collected into a glass tube and used to determine serum lipid levels. The remaining $3 \mathrm{ml}$ was transferred to tubes with anticoagulants $(4.80 \mathrm{~g} / \mathrm{l}$ citric acid, $14.70 \mathrm{~g} / 1$ glucose and $13.20 \mathrm{~g} / \mathrm{l}$ tri-sodium citrate; Shanghai Sangon Biological Engineering Technology \& Services Co.) and used to extract DNA. Measurements of serum TC, TG, HDL-C and LDL-C levels in the samples were performed using enzymatic methods with a Ransod autoanalyzer (Randox Laboratories Ltd., Crumlin, UK and Daiichi Pure Chemicals Co., Ltd., Tokyo, Japan). Serum ApoA1 and ApoB levels were detected using the immunoturbidimetric immunoassay using a commercial kit (Randox Laboratories Ltd.). All determinations were performed with an auto-analyzer (Type 7170A; Hitachi Ltd., Tokyo, Japan) in the Clinical Science Experiment Center of the First Affiliated Hospital, Guangxi Medical University (27-30).

DNA amplification and genotyping. Genomic DNA of the samples was isolated from peripheral blood leukocytes using the phenol-chloroform method (27-30). The extracted DNA was stored at $4^{\circ} \mathrm{C}$ until analysis. Genotyping of the ANGPTL8 rs2278426 SNP was determined by polymerase chain reaction and restriction fragment length polymorphism (PCR-RFLP). PCR amplification was performed using the following primer sequences: Forward 5'-CAGGAGTTCTATTGTGCGGC-3' and reverse 5'-CCTGATGCAACTATCGCACC-3' (Shanghai Sangon Biological Engineering Technology \& Services Co.). Each $25 \mu \mathrm{l}$ PCR reaction mixture consisted of $2 \mu \mathrm{l}$ genomic DNA, $1 \mu 1$ each primer (10 pmol/l), $12.5 \mu 1$ of $2 \mathrm{X}$ Taq PCR 
Table I. Comparison of demographic, lifestyle characteristics and serum lipid levels between the Han and Mulao populations.

\begin{tabular}{|c|c|c|c|c|}
\hline Parameter & Han & Mulao & $\mathrm{t}\left(\chi^{2}\right)$ & P-value \\
\hline No. of patients & 865 & 879 & & \\
\hline Male/female & $425 / 440$ & $407 / 472$ & 1.400 & 0.273 \\
\hline Age (years) & $52.29 \pm 14.26$ & $52.69 \pm 14.99$ & -0.581 & 0.561 \\
\hline Height $(\mathrm{cm})$ & $155.00 \pm 7.96$ & $155.37 \pm 8.13$ & -0.951 & 0.342 \\
\hline Weight (kg) & $54.17 \pm 9.25$ & $52.99 \pm 9.34$ & 2.661 & 0.008 \\
\hline Body mass index $\left(\mathrm{kg} / \mathrm{m}^{2}\right)$ & $22.51 \pm 3.33$ & $21.89 \pm 3.09$ & 4.030 & 0.000 \\
\hline Waist circumference & $74.74 \pm 7.94$ & $75.27 \pm 8.54$ & 1.193 & 0.233 \\
\hline Smoking status (n \%) & & & 8.208 & 0.017 \\
\hline 0 g/day (non-smoker) & $592(68.44)$ & $653(74.29)$ & & \\
\hline$\leq 20$ cigarettes/day & $108(12.49)$ & $80(9.10)$ & & \\
\hline$>20$ cigarettes/day & $165(19.08)$ & $146(16.61)$ & & \\
\hline Alcohol consumption, n (\%) & & & 3.708 & 0.157 \\
\hline 0 g/day (non-drinker) & $650(75.14)$ & $658(74.86)$ & & \\
\hline$\leq 25 \mathrm{~g} /$ day & $3(0.35)$ & $10(1.14)$ & & \\
\hline$>25 \mathrm{~g} / \mathrm{day}$ & $212(24.51)$ & $211(24.00)$ & & \\
\hline Systolic blood pressure (mmHg) & $130.74 \pm 18.52$ & $129.78 \pm 21.86$ & 0.989 & 0.323 \\
\hline Diastolic blood pressure (mmHg) & $82.71 \pm 10.70$ & $81.27 \pm 11.60$ & 2.695 & 0.007 \\
\hline Pulse pressure $(\mathrm{mmHg})$ & $48.03 \pm 14.23$ & $48.51 \pm 16.40$ & -0.654 & 0.513 \\
\hline Glucose (mmol/l) & $6.19 \pm 1.77$ & $6.03 \pm 1.70$ & 1.851 & 0.064 \\
\hline Total cholesterol (mmol/l) & $5.06 \pm 0.95$ & $5.02 \pm 1.11$ & 0.669 & 0.504 \\
\hline Triglyceride (mmol/l) & $1.08(0.80)$ & $1.06(0.79)$ & -1.153 & 0.249 \\
\hline HDL-C (mmol/l) & $1.75 \pm 0.56$ & $1.75 \pm 0.45$ & 0.215 & 0.830 \\
\hline LDL-C (mmol/l) & $2.92 \pm 0.82$ & $2.97 \pm 0.87$ & -1.175 & 0.240 \\
\hline Apo A1 (g/l) & $1.36 \pm 0.26$ & $1.33 \pm 0.40$ & 1.990 & 0.047 \\
\hline ApoB (g/l) & $0.87 \pm 0.20$ & $0.98 \pm 0.57$ & -5.898 & 0.000 \\
\hline ApoA1/ApoB & $1.65 \pm 0.50$ & $1.60 \pm 0.95$ & 1.237 & 0.216 \\
\hline
\end{tabular}

Values of triglycerides were expressed as the median (interquartile range). The difference between the two ethnic groups was determined using the Wilcoxon-Mann-Whitney test. HDL-C, high-density lipoprotein cholesterol; LDL-C, low-density lipoprotein cholesterol; Apo, Apolipoprotein.

Master mix (constituent: $20 \mathrm{mM}$ Tris- $\mathrm{HCl}, \mathrm{pH} 8.3,100 \mathrm{mM}$ $\mathrm{KCl}, 3 \mathrm{mM} \mathrm{MgCl} \mathrm{ma}_{2}, 0.1 \mathrm{U}$ Taq Polymerase/ $\mu \mathrm{l}, 500 \mu \mathrm{M}$ dNTP each; Shanghai Sangon Biological Engineering Technology \& Services Co.), and $8.5 \mu \mathrm{l}$ of $\mathrm{ddH}_{2} \mathrm{O}$ (DNase/RNase-free). PCR was performed with an initialization step of $95^{\circ} \mathrm{C}$ for $7 \mathrm{~min}$, followed by $45 \mathrm{sec}$ denaturing at $95^{\circ} \mathrm{C}, 45 \mathrm{sec}$ of annealing at $60^{\circ} \mathrm{C}$ and $1 \mathrm{~min}$ of elongation at $72^{\circ} \mathrm{C}$ for 33 cycles. The amplification was completed with a final extension at $72^{\circ} \mathrm{C}$ for $7 \mathrm{~min}$. Following electrophoresis on a $2.0 \%$ agarose gel with $0.5 \mu \mathrm{g} / \mathrm{ml}$ ethidium bromide, the amplification products were visualized under ultraviolet light. Subsequently, each restriction enzyme reaction was performed with $5 \mu$ amplified DNA, $7.5 \mu$ l nuclease-free water, $1 \mu \mathrm{l}$ of $10 \mathrm{X}$ buffer solution and 5 units BseGI (BtsCI) (Shanghai Sangon Biological Engineering Technology \& Services Co.) restriction enzyme in a total volume of $15 \mu \mathrm{l}$, digested at $55^{\circ} \mathrm{C}$ overnight. Following restriction enzyme digestion of the amplified DNA, genotypes of the digestive products were identified using electrophoresis on $2 \%$ ethidium-bromide stained agarose gels and visualized under ultraviolet light. Genotypes were identified by an experienced technician blinded to the epidemiological and serum lipid results.

DNA sequencing. The six samples (AA, AG and GG genotypes in the two ethnic groups) detected by the PCR-RFLP were also confirmed by direct sequencing. The PCR product was purified by low melting point gel electrophoresis and phenol extraction and then the DNA sequences were analyzed by Shanghai Sangon Biological Engineering Technology \& Services Co.

Diagnostic criteria. The normal values of serum TC, TG, HDL-C, LDL-C, ApoA1, ApoB levels and the ApoA1/ApoB ratio in our Clinical Science Experiment Center were 3.10-5.17, 0.56-1.70, 1.16-1.42, 2.70-3.10 mmol/1, 1.20-1.60, 0.80-1.05 g/l and 1.00-2.50, respectively. The 
Table II. Comparison of the genotype and allelic frequencies of angiopoietin-like protein 8 rs2278426 SNP in the Han and Mulao populations.

\begin{tabular}{|c|c|c|c|c|c|c|c|c|c|c|}
\hline \multirow[b]{2}{*}{ Group } & \multirow[b]{2}{*}{$\mathrm{n}$} & \multicolumn{5}{|c|}{ Genotype, n (\%) } & \multicolumn{4}{|c|}{ Allele, n (\%) } \\
\hline & & GG & GA & AA & $\chi^{2}$ & P-value & $\mathrm{G}$ & A & $\chi^{2}$ & P-value \\
\hline Han + & 865 & 595 (68.79) & $232(26.82)$ & $38(4.39)$ & 13.671 & 0.001 & $1422(82.20)$ & $308(17.80)$ & 14.688 & 0.000 \\
\hline Mulao & 879 & $533(60.64)$ & $287(32.65)$ & $59(6.71)$ & & & $1353(76.96)$ & $405(23.04)$ & & \\
\hline \multicolumn{11}{|l|}{ Han } \\
\hline Male & 425 & $288(67.76)$ & $120(28.24)$ & $17(4.00)$ & 1.044 & 0.593 & $696(81.88)$ & 154 (18.12) & 0.113 & 0.737 \\
\hline Female & 440 & 307 (69.77) & $112(25.46)$ & $21(4.77)$ & & & $726(82.50)$ & $154(17.50)$ & & \\
\hline \multicolumn{11}{|l|}{ Mulao } \\
\hline Male & 407 & $243(59.70)$ & $129(31.70)$ & $35(8.60)$ & 4.343 & 0.114 & 615 (75.55) & $199(24.45)$ & 1.699 & 0.192 \\
\hline Female & 472 & $290(61.44)$ & $158(33.48)$ & $24(5.08)$ & & & 738 (78.18) & $206(21.82)$ & & \\
\hline
\end{tabular}

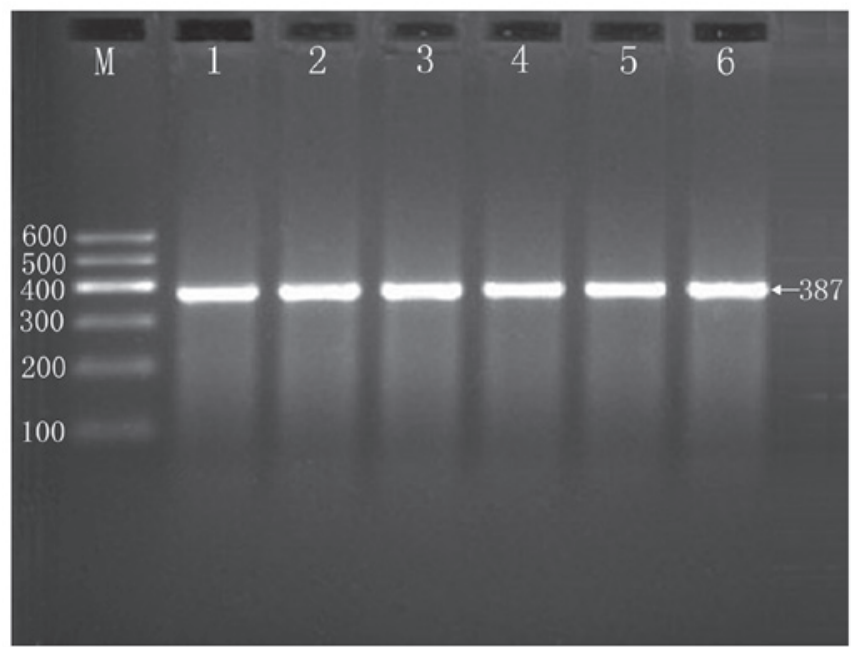

Figure 1. Electrophoresis of polymerase chain reaction products of the samples. Lane $\mathrm{M}$ is the $100 \mathrm{bp}$ marker ladder; Lane 1-5 are samples, the $387 \mathrm{bp}$ bands are the target genes.

individuals with $\mathrm{TC}>5.17 \mathrm{mmol} / 1$ and/or $\mathrm{TG}>1.70 \mathrm{mmol} / \mathrm{l}$ were defined as hyperlipidemic $(33,34)$. Hypertension was diagnosed according to the criteria of the 1999 and 2003 World Health Organization-International Society of Hypertension Guidelines for the management of hypertension (35-37). The Cooperative Meta-analysis Group of China Obesity Task Force criteria were used for diagnosing an individual as overweight or obese (38). Normal weight, overweight and obese were defined as a BMI of $<24,24-28$ or $>28 \mathrm{~kg} / \mathrm{m}^{2}$, respectively (39).

Statistical analysis. Epidemiological data were recorded on a pre-designed form and managed with Microsoft Excel software (Microsoft, Redmond, WA, USA). All calculations were performed using SPSS software version 19.0 (IMB, Armonk, NY, USA) statistical package. The mean \pm standard deviation (serum TG levels were presented as medians and interquartile ranges) and frequencies of baseline characteristics were calculated. Comparison of numerical variables, including age and body mass index, between the two groups was assessed using Student's unpaired t-test. Categorical variables were analyzed with a $\chi^{2}$ test or Fisher's exact test. Allele frequency

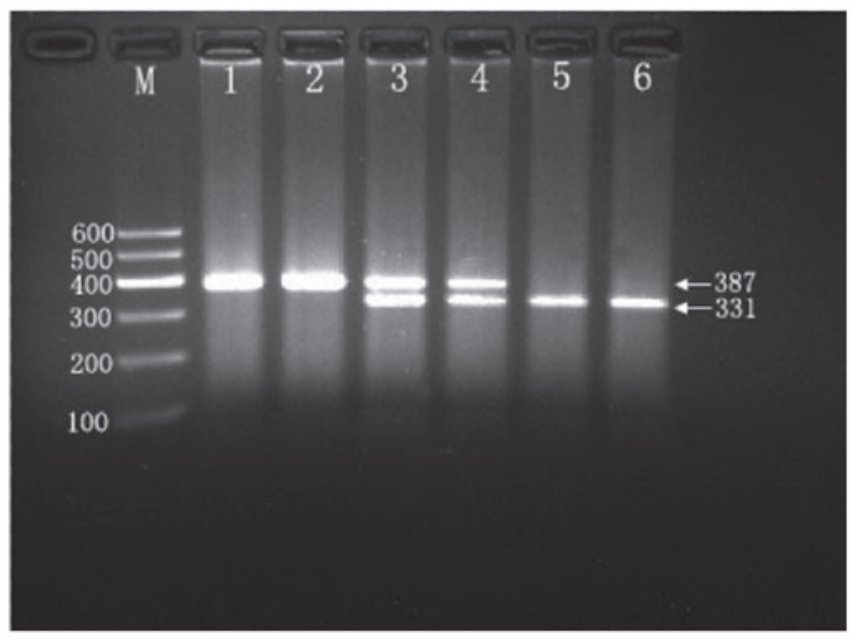

Figure 2. Genotyping of the angiopoietin-like protein 8 rs2278426 SNP. Lane $\mathrm{M}$ is the 100 bp marker Ladder; Lanes 1 and 2, GG genotype (387 bp); Lanes 3 and 4, AG genotype (387, 331 and 56 bp); and lanes 5 and 6, AA genotype (331 and $56 \mathrm{bp}$ ). The $56 \mathrm{bp}$ segment is not visible in the gel owing to its fast migration speed.

was determined via direct counting and the standard goodness-of-fit test was used to test the Hardy-Weinberg equilibrium. Differences in genotype distribution between the groups were calculated using the $\chi^{2}$ test. The association of genotypes and serum lipid parameters were determined using analysis of covariance. Gender, age, BMI, blood pressure, alcohol consumption and cigarette smoking were adjusted for statistical analysis. Multivariate linear regression analysis with stepwise modeling was performed to evaluate the association of serum lipid levels with genotypes (GA/AA=1 and $\mathrm{GG}=2)$ and several environmental factors in the combined population and in, Mulao and Han groups, as well as males and females separately. $\mathrm{P}<0.05$ was considered to indicate a statistically significant difference.

\section{Results}

General characteristics and serum lipid levels. The comparison of general characteristics and serum lipid levels between the Mulao and Han populations is summarized in Table I. 


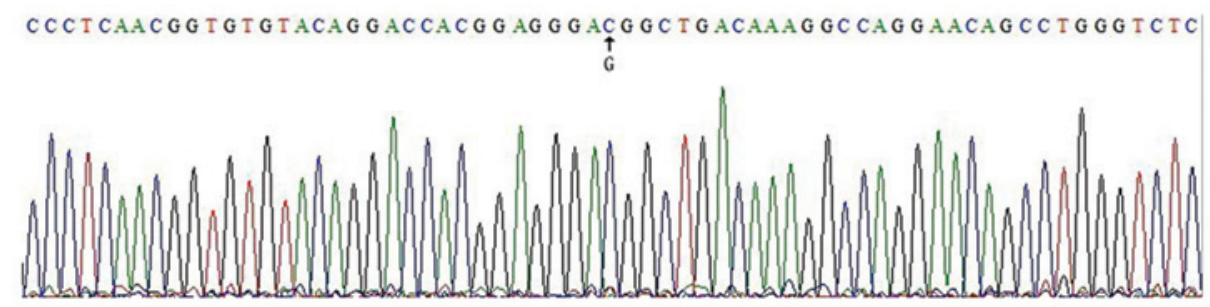

B

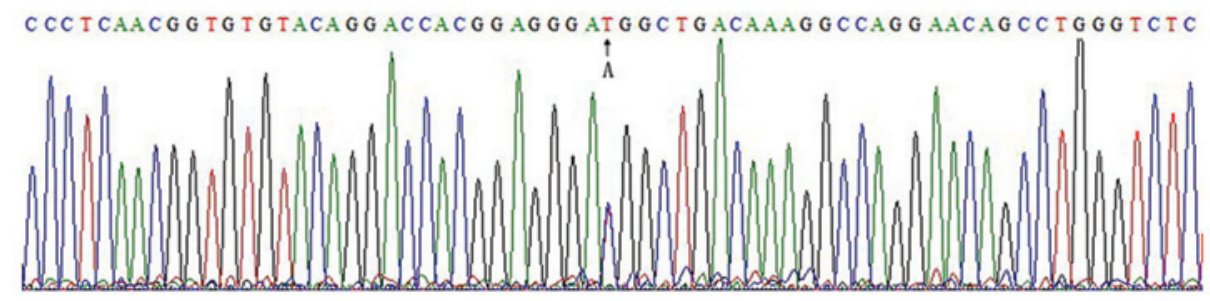

C

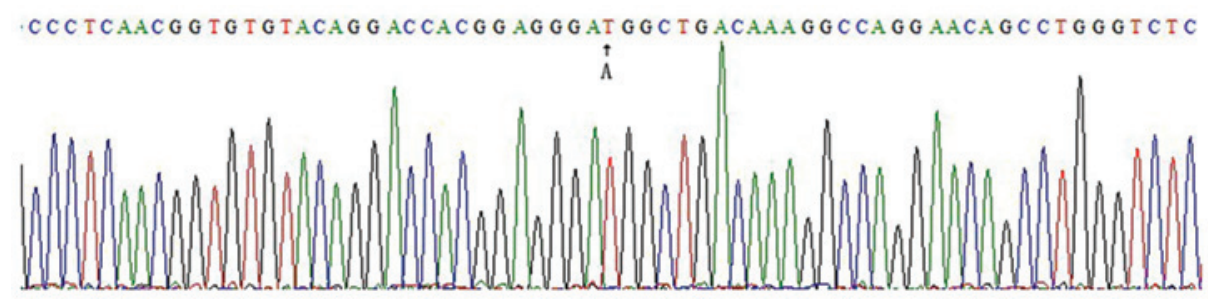

Figure 3. Nucleotide reverse sequence for part of angiopoietin-like protein 8 rs2278426. (A) GG genotype; (B) GA genotype; (C) AA genotype.

Body weight, BMI, cigarette smoking levels and diastolic blood pressure were all lower in the Mulao population than in the Han population $(\mathrm{P}<0.05-0.001)$, whereas the levels of ApoB were higher in the Mulao individuals than in the Han individuals $(\mathrm{P}<0.001)$ and the level of ApoA1 was higher in the Han individuals than in the Mulao individuals $(\mathrm{P}<0.05)$. No significant differences were identified in the levels of systolic blood pressure, serum TC, TG, HDL-C, LDL-C, the ApoA1/ApoB ratio, age structure, gender ratio, height and the amount of alcohol consumption between the two ethnic groups ( $\mathrm{P}>0.05$ for all).

Results of electrophoresis and genotyping. After the genomic DNA of the samples was amplified using PCR and visualized with $2 \%$ agarose gel electrophoresis, products of $387 \mathrm{bp}$ nucleotide sequences were observed in all samples (Fig. 1). The genotypes identified were termed according to the presence (A allele) or absence ( $\mathrm{G}$ allele) of the enzyme restriction sites. Thus, the AA genotype is homozygous for the presence of the site (bands at 331 and 56 bp), the GA genotype is heterozygous for the presence and absence of the site (bands at 387, 331 and $56 \mathrm{bp}$ ) and the GG genotype is homozygous for the absence of the site (bands at 387 bp; Fig. 2). The 56 bp segment is not visible in the gel owing to its fast migratory speed. The genotypes of the rs2278426 SNP are in Hardy-Weinberg equilibrium.

Results of sequencing. The results are presented as GG, GA and AA genotypes by PCR-RFLP, and the GG, GA and AA genotypes were also confirmed by reverse sequencing (Fig. 3), respectively. The reverse sequence used as the SNP site was upstream of the sequence, therefore the same base pairs in a row in front of the PCR products influence forward sequencing.
Genotypic and allelic frequencies. The genotypic and allelic frequencies of the rs2278426 SNP in the ANGPTL8 gene are shown in Table II. The frequencies of $\mathrm{G}$ and $\mathrm{A}$ alleles were 82.20 and $17.80 \%$ in Han, and 76.96 and $23.04 \%$ in Mulao populations $(\mathrm{P}<0.001)$, respectively. The frequencies of $\mathrm{GG}$, GA and AA genotypes were 68.79, 26.82 and $4.39 \%$ in the Han population and $60.64,32.65$ and $6.71 \%$ in the Mulao population $(\mathrm{P}<0.005)$, respectively. No differences in the genotypic frequencies between males and females in the two ethnic groups ( $\mathrm{P}>0.05$ for each) were identified.

Genotypes and serum lipid levels. As shown in Tables III and IV, serum LDL-C, ApoA1 and ApoB levels and the ApoA1/ApoB ratio in the Han but not in the Mulao population were different among the genotypes $(\mathrm{P}<0.05-0.001)$. The subjects with the GA/AA genotypes had lower LDL-C and ApoB levels, and higher ApoA1 levels and a higher ApoA1/ApoB ratio than the subjects with the GG genotype. No differences were observed in serum lipid levels between the genotypes in the Mulao population $(\mathrm{P}>0.05)$. Subgroup analyses revealed that serum TC, LDL-C, ApoB levels and the ApoA1/ApoB ratio in Han females but not in males were different among the genotypes $(\mathrm{P}<0.05-0.001)$, the subjects with the GA/AA genotype had lower TC, LDL-C and ApoB levels, and a higher ApoA1/ApoB ratio than the subjects with the GG genotype $(\mathrm{P}<0.05-0.001)$. No differences in serum lipid levels were identified between the specific genotypes in Mulao females or males ( $\mathrm{P}>0.05$ for each).

Relative factors for serum lipid parameters. The multiple linear regression analysis revealed that LDL-C, ApoA1, ApoB levels and the ApoA1/ApoB ratio in the Han population were correlated with the specific genotypes $(\mathrm{P}<0.05-0.001$; 
Table III. Comparison of the genotypes and serum lipid levels in the Han and Mulao populations.

\begin{tabular}{|c|c|c|c|c|c|c|c|c|}
\hline Genotype & $\mathrm{n}$ & $\begin{array}{c}\mathrm{TC} \\
(\mathrm{mmol} / \mathrm{l})\end{array}$ & $\begin{array}{c}\mathrm{TG} \\
(\mathrm{mmol} / \mathrm{l})\end{array}$ & $\begin{array}{l}\text { HDL-C } \\
(\mathrm{mmol} / \mathrm{l})\end{array}$ & $\begin{array}{l}\text { LDL-C } \\
(\mathrm{mmol} / \mathrm{l})\end{array}$ & $\begin{array}{c}\text { ApoA1 } \\
(\mathrm{g} / \mathrm{l})\end{array}$ & $\begin{array}{c}\text { ApoB } \\
(\mathrm{g} / / 1)\end{array}$ & $\begin{array}{c}\text { ApoA1/ } \\
\text { ApoB }\end{array}$ \\
\hline \multicolumn{9}{|l|}{ Han } \\
\hline GG & 595 & $5.08 \pm 0.96$ & $1.09(0.80)$ & $1.74 \pm 0.61$ & $2.96 \pm 0.81$ & $1.34 \pm 0.26$ & $0.88 \pm 0.19$ & $1.61 \pm 0.47$ \\
\hline GA/AA & 270 & $4.99 \pm 0.94$ & $1.02(0.78)$ & $1.77 \pm 0.42$ & $2.84 \pm 0.86$ & $1.39 \pm 0.25$ & $0.85 \pm 0.21$ & $1.74 \pm 0.55$ \\
\hline F-value & & 3.397 & 0.040 & 3.051 & 5.816 & 4.268 & 8.186 & 12.161 \\
\hline P-value & & 0.065 & 0.841 & 0.081 & 0.016 & 0.039 & 0.004 & 0.000 \\
\hline \multicolumn{9}{|l|}{ Mulao } \\
\hline GG & 533 & $5.04 \pm 1.11$ & $1.04(0.76)$ & $1.76 \pm 0.47$ & $2.97 \pm 0.87$ & $1.33 \pm 0.40$ & $0.97 \pm 0.56$ & $1.62 \pm 1.02$ \\
\hline GA/AA & 346 & $5.00 \pm 1.12$ & $1.09(0.84)$ & $1.73 \pm 0.41$ & $2.96 \pm 0.88$ & $1.33 \pm 0.39$ & $1.00 \pm 0.58$ & $1.58 \pm 0.84$ \\
\hline F-value & & -0.190 & -1.344 & -1.312 & -0.048 & -0.571 & -0.647 & -0.857 \\
\hline P-value & & 0.849 & 0.179 & 0.189 & 0.962 & 0.568 & 0.518 & 0.392 \\
\hline
\end{tabular}

Value of TGs were expressed as the (interquartile range). The difference between the genotypes was determined using the Wilcoxon-Mann-Whitney test. TC, total cholesterol; TG, triglyceride; HDL-C, high-density lipoprotein cholesterol; LDL-C, low-density lipoprotein cholesterol; ApoA1, Apolipoprotein A1; ApoB, Apolipoprotein B; ApoA1/ApoB, the ratio of Apolipoprotein A1 to Apolipoprotein B.

Table IV. Comparison of the genotypes and serum lipid levels between males and females in the Han and Mulao populations.

\begin{tabular}{|c|c|c|c|c|c|c|c|c|}
\hline $\begin{array}{l}\text { Ethnicity/ } \\
\text { genotype }\end{array}$ & $\mathrm{n}$ & $\begin{array}{c}\mathrm{TC} \\
(\mathrm{mmol} / \mathrm{l})\end{array}$ & $\begin{array}{c}\mathrm{TG} \\
(\mathrm{mmol} / \mathrm{l})\end{array}$ & $\begin{array}{l}\text { HDL-C } \\
(\mathrm{mmol} / \mathrm{l})\end{array}$ & $\begin{array}{l}\text { LDL-C } \\
(\mathrm{mmol} / \mathrm{l})\end{array}$ & $\begin{array}{c}\text { ApoA1 } \\
(\mathrm{g} / \mathrm{l})\end{array}$ & $\begin{array}{c}\text { ApoB } \\
(\mathrm{g} / \mathrm{l})\end{array}$ & $\begin{array}{c}\text { ApoA1/ } \\
\text { ApoB }\end{array}$ \\
\hline \multicolumn{9}{|l|}{ Han/male } \\
\hline GG & 288 & $4.96 \pm 0.98$ & $1.07(0.77)$ & $1.71 \pm 0.43$ & $2.85 \pm 0.80$ & $1.35 \pm 0.26$ & $0.84 \pm 0.16$ & $1.66 \pm 0.43$ \\
\hline GA/AA & 137 & $4.95 \pm 0.86$ & $1.07(0.71)$ & $1.76 \pm 0.42$ & $2.75 \pm 0.89$ & $1.38 \pm 0.24$ & $0.83 \pm 0.19$ & $1.76 \pm 0.55$ \\
\hline F-value & & -0.070 & -0.229 & -1.271 & -1.280 & -1.343 & -0.871 & -1.451 \\
\hline P-value & & 0.944 & 0.819 & 0.204 & 0.201 & 0.179 & 0.384 & 0.147 \\
\hline \multicolumn{9}{|c|}{ Han/female } \\
\hline $\mathrm{GG}$ & 307 & $5.20 \pm 0.92$ & $1.09(0.83)$ & $1.78 \pm 0.74$ & $3.06 \pm 0.80$ & $1.34 \pm 0.25$ & $0.91 \pm 0.21$ & $1.56 \pm 0.50$ \\
\hline GA/AA & 133 & $5.04 \pm 1.01$ & $0.98(0.83)$ & $1.79 \pm 0.42$ & $2.93 \pm 0.82$ & $1.39 \pm 0.27$ & $0.86 \pm 0.22$ & $1.73 \pm 0.55$ \\
\hline F-value & & -2.464 & -0.594 & -1.256 & -2.197 & -1.561 & -3.216 & -3.578 \\
\hline P-value & & 0.014 & 0.553 & 0.209 & 0.028 & 0.119 & 0.001 & 0.000 \\
\hline \multicolumn{9}{|c|}{ Mulao/male } \\
\hline $\mathrm{GG}$ & 243 & $5.07 \pm 1.01$ & $1.08(0.77)$ & $1.76 \pm 0.53$ & $2.94 \pm 0.82$ & $1.35 \pm 0.42$ & $1.03 \pm 0.62$ & $1.53 \pm 0.676$ \\
\hline GA/AA & 164 & $5.03 \pm 1.17$ & $1.16(0.86)$ & $1.70 \pm 0.42$ & $2.95 \pm 0.83$ & $1.32 \pm 0.40$ & $1.04 \pm 0.63$ & $1.50 \pm 0.69$ \\
\hline F-value & & -0.115 & -1.131 & -1.484 & -0.144 & -1.375 & -0.015 & -1.098 \\
\hline P-value & & 0.908 & 0.258 & 0.138 & 0.886 & 0.169 & 0.988 & 0.272 \\
\hline \multicolumn{9}{|c|}{ Mulao/female } \\
\hline GG & 290 & $5.01 \pm 1.18$ & $1.01(0.76)$ & $1.76 \pm 0.42$ & $2.99 \pm 0.91$ & $1.31 \pm 0.39$ & $0.93 \pm 0.50$ & $1.68 \pm 1.24$ \\
\hline GA/AA & 182 & $5.00 \pm 1.08$ & $1.04(0.82)$ & $1.76 \pm 0.40$ & $2.97 \pm 0.91$ & $1.34 \pm 0.37$ & $0.96 \pm 0.53$ & $1.66 \pm 0.94$ \\
\hline F-value & & -0.185 & -0.744 & -0.301 & -0.091 & -0.645 & -0.846 & -0.190 \\
\hline P-value & & 0.853 & 0.457 & 0.763 & 0.928 & 0.519 & 0.398 & 0.849 \\
\hline
\end{tabular}

Value of TGs were expressed as the median (interquartile range). The difference between the genotypes was determined by the Wilcoxon-Mann-Whitney test. TC, total cholesterol; TG, triglyceride; HDL-C, high-density lipoprotein cholesterol; LDL-C, low-density lipoprotein cholesterol; ApoA1, Apolipoprotein A1; ApoB, Apolipoprotein B; ApoA1/ApoB, the ratio of Apolipoprotein A1 to Apolipoprotein B.

Table V). As shown in Table VI, when serum lipid data were analyzed according to gender, TC, LDL-C and ApoB levels and the ApoA1/ApoB ratio in Han females were correlated with specific genotypes $(\mathrm{P}<0.05-0.001)$. Serum lipid param- eters were also associated with age, gender, BMI, systolic and diastolic blood pressure, fasting blood glucose levels, cigarette smoking and alcohol consumption in the two ethnic groups $(\mathrm{P}<0.05-0.001$, Tables V and VI). 
Table V. Association between serum lipid parameters and relative factors in the Han and Mulao populations.

A, Han and Mulao

\begin{tabular}{|c|c|c|c|c|c|c|}
\hline Lipid parameter & Risk factor & $\mathrm{B}$ & Std. error & $\beta$ & $\mathrm{t}$ & P-value \\
\hline \multirow[t]{5}{*}{$\mathrm{TC}$} & Age & 0.010 & 0.002 & 0.136 & 5.520 & 0.000 \\
\hline & Alcohol consumption & 0.070 & 0.029 & 0.058 & 2.446 & 0.015 \\
\hline & Diastolic blood pressure & 0.008 & 0.002 & 0.085 & 3.453 & 0.001 \\
\hline & Body mass index & 0.043 & 0.008 & 0.135 & 5.587 & 0.000 \\
\hline & Glucose & 0.021 & 0.014 & 0.035 & 1.466 & 0.143 \\
\hline \multirow[t]{6}{*}{ TG } & Waist circumference & 0.048 & 0.004 & 0.304 & 13.099 & 0.000 \\
\hline & Cigarette smoking & 0.218 & 0.038 & 0.129 & 5.770 & 0.000 \\
\hline & Diastolic blood pressure & 0.008 & 0.003 & 0.070 & 2.982 & 0.003 \\
\hline & Ethnic group & -0.155 & 0.059 & -0.059 & -2.643 & 0.008 \\
\hline & Glucose & 0.053 & 0.017 & 0.070 & 3.023 & 0.003 \\
\hline & Age & -0.004 & 0.002 & -0.044 & -1.891 & 0.059 \\
\hline \multirow[t]{5}{*}{ HDL-C } & Waist circumference & -0.008 & 0.002 & -0.1260 & -3.787 & 0.000 \\
\hline & Alcohol consumption & 0.094 & 0.017 & 0.158 & 5.572 & 0.000 \\
\hline & Gender & 0.120 & 0.029 & 0.119 & 4.132 & 0.000 \\
\hline & Age & 0.002 & 0.001 & 0.047 & 2.007 & 0.045 \\
\hline & Body mass index & -0.018 & 0.005 & -0.113 & -3.460 & 0.001 \\
\hline \multirow[t]{4}{*}{ LDL-C } & Age & 0.009 & 0.001 & 0.147 & 6.135 & 0.000 \\
\hline & Body mass index & 0.044 & 0.006 & 0.166 & 7.053 & 0.000 \\
\hline & Ethnic group & 0.077 & 0.040 & 0.045 & 1.920 & 0.055 \\
\hline & Glucose & 0.026 & 0.012 & 0.053 & 2.220 & 0.027 \\
\hline \multirow[t]{3}{*}{ ApoA1 } & Alcohol consumption & 0.103 & 0.011 & 0.265 & 9.287 & 0.000 \\
\hline & Body mass index & -0.010 & 0.002 & -0.096 & -4.062 & 0.000 \\
\hline & Gender & 0.068 & 0.019 & 0.101 & 3.564 & 0.000 \\
\hline \multirow[t]{3}{*}{ ApoB } & Waist circumference & 0.010 & 0.001 & 0.196 & 8.411 & 0.000 \\
\hline & Ethnic group & 0.126 & 0.020 & 0.147 & 6.337 & 0.000 \\
\hline & Glucose & 0.021 & 0.006 & 0.086 & 3.682 & 0.000 \\
\hline \multirow[t]{7}{*}{ ApoA1/ApoB } & Waist circumference & -0.011 & 0.003 & -0.114 & -3.394 & 0.001 \\
\hline & Glucose & -0.021 & 0.011 & -0.048 & -1.973 & 0.049 \\
\hline & Body mass index & -0.026 & 0.008 & -0.110 & -3.323 & 0.001 \\
\hline & Alcohol consumption & 0.105 & 0.025 & 0.118 & 4.146 & 0.000 \\
\hline & Gender & 0.172 & 0.044 & 0.113 & 3.920 & 0.000 \\
\hline & Ethnic group & -0.071 & 0.036 & -0.046 & -1.975 & 0.048 \\
\hline & Age & -0.004 & 0.001 & -0.068 & -2.837 & 0.005 \\
\hline
\end{tabular}

B, Han

\begin{tabular}{|c|c|c|c|c|c|c|}
\hline Lipid parameter & Risk factor & $\mathrm{B}$ & Std. error & $\beta$ & $\mathrm{t}$ & P-value \\
\hline \multirow[t]{5}{*}{$\mathrm{TC}$} & Waist circumference & 0.016 & 0.004 & 0.130 & 3.759 & 0.000 \\
\hline & Age & 0.009 & 0.002 & 0.137 & 3.876 & 0.000 \\
\hline & Alcohol consumption & 0.104 & 0.037 & 0.094 & 2.777 & 0.006 \\
\hline & Diastolic blood pressure & 0.013 & 0.003 & 0.151 & 4.321 & 0.000 \\
\hline & Glucose & 0.024 & 0.018 & 0.045 & 1.324 & 0.186 \\
\hline \multirow[t]{5}{*}{ TG } & Waist circumference & 0.061 & 0.006 & 0.314 & 9.739 & 0.000 \\
\hline & Cigarette smoking & 0.393 & 0.061 & 0.201 & 6.460 & 0.000 \\
\hline & Glucose & 0.114 & 0.029 & 0.130 & 4.006 & 0.000 \\
\hline & Diastolic blood pressure & 0.011 & 0.005 & 0.076 & 2.302 & 0.022 \\
\hline & Age & -0.07 & 0.004 & -0.062 & -1.876 & 0.061 \\
\hline HDL-C & Waist circumference & -0.013 & 0.002 & -0.186 & -5.348 & 0.000 \\
\hline
\end{tabular}


Table V. Continued.

\begin{tabular}{|c|c|c|c|c|c|c|}
\hline Lipid parameter & Risk factor & B & Std. error & $\beta$ & $\mathrm{t}$ & P-value \\
\hline & Gender & 0.138 & 0.045 & 0.123 & 3.082 & 0.002 \\
\hline & Alcohol consumption & 0.080 & 0.026 & 0.123 & 3.078 & 0.002 \\
\hline \multirow[t]{4}{*}{ LDL-C } & Age & 0.010 & 0.002 & 0.172 & 5.010 & 0.000 \\
\hline & Body mass index & 0.041 & 0.008 & 0.164 & 4.962 & 0.000 \\
\hline & Glucose & 0.035 & 0.016 & 0.074 & 2.157 & 0.031 \\
\hline & Genotype & 0.019 & 0.048 & 0.013 & 11.857 & 0.000 \\
\hline \multirow[t]{5}{*}{ ApoA1 } & Alcohol consumption & 0.091 & 0.012 & 0.304 & 7.685 & 0.000 \\
\hline & Body mass index & -0.017 & 0.003 & -0.225 & -6.812 & 0.000 \\
\hline & Gender & -0.014 & 0.007 & -0.028 & -2.109 & 0.035 \\
\hline & Cigarette smoking & 0.047 & 0.013 & 0.145 & 3.536 & 0.000 \\
\hline & Genotype & 0.077 & 0.022 & 0.150 & 3.476 & 0.001 \\
\hline \multirow[t]{6}{*}{ ApoB } & Waist circumference & 0.006 & 0.001 & 0.230 & 5.374 & 0.000 \\
\hline & Glucose & 0.015 & 0.003 & 0.136 & 4.363 & 0.000 \\
\hline & Alcohol consumption & 0.022 & 0.007 & 0.097 & 3.028 & 0.003 \\
\hline & Systolic blood pressure & 0.001 & 0.000 & 0.136 & 4.311 & 0.000 \\
\hline & Body mass index & 0.007 & 0.002 & 0.124 & 2.912 & 0.004 \\
\hline & Genotype & 0.001 & 0.011 & 0.004 & 1.025 & 0.035 \\
\hline \multirow[t]{7}{*}{ ApoA1/ApoB } & Waist circumference & -0.010 & 0.003 & -0.162 & -3.658 & 0.000 \\
\hline & Systolic blood pressure & -0.002 & 0.001 & -0.084 & -2.552 & 0.011 \\
\hline & Glucose & -0.014 & 0.009 & -0.049 & -1.506 & 0.132 \\
\hline & Body mass index & -0.031 & 0.007 & -0.205 & -4.653 & 0.000 \\
\hline & Cigarette smoking & 0.063 & 0.020 & 0.100 & 3.082 & 0.002 \\
\hline & Gender & 0.126 & 0.041 & 0.126 & 3.068 & 0.002 \\
\hline & Genotype & -0.030 & 0.011 & -0.027 & -2.731 & 0.006 \\
\hline
\end{tabular}

C, Mulao

\begin{tabular}{|c|c|c|c|c|c|c|}
\hline Lipid parameter & Risk factor & $\mathrm{B}$ & Std. error & $\beta$ & $\mathrm{t}$ & P-value \\
\hline \multirow[t]{2}{*}{$\mathrm{TC}$} & Age & 0.010 & 0.002 & 0.138 & 4.163 & 0.000 \\
\hline & Body mass index & 0.053 & 0.012 & 0.148 & 4.465 & 0.000 \\
\hline \multirow[t]{2}{*}{ TG } & Waist circumference & 0.037 & 0.004 & 0.309 & 9.603 & 0.000 \\
\hline & Alcohol consumption & 0.114 & 0.038 & 0.096 & 2.996 & 0.003 \\
\hline \multirow[t]{4}{*}{ HDL-C } & Waist circumference & -0.007 & 0.002 & -0.129 & -2.738 & 0.006 \\
\hline & Alcohol consumption & 0.065 & 0.017 & 0.123 & 3.747 & 0.000 \\
\hline & Body mass index & -0.023 & 0.007 & -0.159 & -3.423 & 0.001 \\
\hline & Age & 0.002 & 0.001 & 0.052 & 1.586 & 0.113 \\
\hline \multirow[t]{2}{*}{ LDL-C } & Age & 0.007 & 0.002 & 0.128 & 3.877 & 0.000 \\
\hline & Body mass index & 0.048 & 0.009 & 0.170 & 5.160 & 0.000 \\
\hline ApoA1/ApoB & Alcohol consumption & 0.079 & 0.015 & 0.171 & 5.142 & 0.000 \\
\hline
\end{tabular}

TC, total cholesterol; TG, triglyceride; HDL-C, high-density lipoprotein cholesterol; LDL-C, low-density lipoprotein cholesterol; ApoA1, Apolipoprotein A1; ApoB, Apolipoprotein B; ApoA1/ApoB, the ratio of Apolipoprotein A1 to Apolipoprotein B; Std. error, standard error.

\section{Discussion}

In the present study, it was revealed that the serum ApoB level was higher but serum ApoA1 level was lower in the Mulao population than in the Han population. No significant differences in the levels of TC, HDL-C and LDL-C, and the ApoA1/ApoB ratio between the two ethnic groups were observed. These findings differ marginally from those of our previous studies (28-31). This difference may be associated with the sampling method. In addition, dyslipidemia is affected by 
Table VI. Association between serum lipid parameters and relative factors in the males and females of the Han and Mulao populations.

\begin{tabular}{|c|c|c|c|c|c|c|}
\hline Lipid parameter & Risk factor & $\mathrm{B}$ & Std. error & $\beta$ & $\mathrm{t}$ & P-value \\
\hline \multirow[t]{3}{*}{ TC } & Diastolic blood pressure & 0.024 & 0.004 & 0.284 & 6.099 & 0.000 \\
\hline & Alcohol consumption & 0.098 & 0.042 & 0.109 & 2.324 & 0.021 \\
\hline & Glucose & 0.029 & 0.023 & 0.059 & 1.259 & 0.209 \\
\hline \multirow[t]{4}{*}{ TG } & Waist circumference & 0.080 & 0.010 & 0.355 & 7.793 & 0.000 \\
\hline & Cigarette smoking & 0.487 & 0.093 & 0.234 & 5.250 & 0.000 \\
\hline & Diastolic blood pressure & 0.002 & 0.008 & 0.012 & 0.272 & 0.785 \\
\hline & Glucose & 0.080 & 0.045 & 0.079 & -1.769 & 0.078 \\
\hline \multirow[t]{2}{*}{ HDL-C } & Body mass index & -0.035 & 0.006 & -0.299 & -6.302 & 0.000 \\
\hline & Alcohol consumption & 0.081 & 0.020 & 0.190 & 4.016 & 0.000 \\
\hline \multirow[t]{2}{*}{ LDL-C } & Cigarette smoking & -0.181 & 0.043 & -0.196 & -4.153 & 0.000 \\
\hline & Body mass index & 0.034 & 0.010 & 0.151 & 3.207 & 0.001 \\
\hline \multirow[t]{3}{*}{ ApoA1 } & Alcohol consumption & 0.094 & 0.013 & 0.336 & 7.236 & 0.000 \\
\hline & Body mass index & -0.019 & 0.004 & -0.247 & -5.439 & 0.000 \\
\hline & Cigarette smoking & 0.048 & 0.014 & 0.0151 & 3.343 & 0.001 \\
\hline \multirow[t]{5}{*}{ ApoB } & Body mass index & 0.008 & 0.003 & 0.153 & 2.716 & 0.007 \\
\hline & Glucose & 0.017 & 0.005 & 0.160 & 3.641 & 0.000 \\
\hline & Alcohol consumption & 0.019 & 0.009 & 0.099 & 2.217 & 0.027 \\
\hline & Diastolic blood pressure & 0.004 & 0.001 & 0.209 & 4.636 & 0.000 \\
\hline & Waist circumference & 0.004 & 0.001 & 0.179 & 3.188 & 0.002 \\
\hline \multirow[t]{3}{*}{ ApoA1/ApoB } & Body mass index & -0.053 & 0.006 & -0.386 & -8.525 & 0.000 \\
\hline & Cigarette smoking & 0.086 & 0.026 & 0.151 & 3.367 & 0.001 \\
\hline & Alcohol consumption & 0.088 & 0.023 & 0.176 & 3.820 & 0.000 \\
\hline
\end{tabular}

B, Han/female

\begin{tabular}{|c|c|c|c|c|c|c|}
\hline Lipid parameter & Risk factor & $\mathrm{B}$ & Std. error & $\beta$ & $\mathrm{t}$ & P-value \\
\hline \multirow[t]{4}{*}{$\mathrm{TC}$} & Alcohol consumption & -0.113 & 0.170 & -0.030 & -0.665 & 0.506 \\
\hline & Age & 0.024 & 0.003 & 0.320 & 7.017 & 0.000 \\
\hline & Body mass index & 0.058 & 0.015 & 0.172 & 3.781 & 0.000 \\
\hline & Genotype & 0.072 & 0.036 & 0.035 & 1.982 & 0.048 \\
\hline \multirow[t]{3}{*}{ TG } & Waist circumference & 0.045 & 0.007 & 0.278 & 6.135 & 0.000 \\
\hline & Diastolic blood pressure & 0.017 & 0.005 & 0.147 & 3.262 & 0.001 \\
\hline & Glucose & 0.122 & 0.030 & 0.177 & 4.019 & 0.000 \\
\hline HDL-C & Waist circumference & -0.008 & 0.004 & -0.093 & 1.951 & 0.052 \\
\hline \multirow[t]{4}{*}{ LDL-C } & Body mass index & 0.049 & 0.013 & 0.170 & 3.753 & 0.000 \\
\hline & Age & 0.021 & 0.003 & 0.324 & 7.109 & 0.000 \\
\hline & Alcohol consumption & -0.218 & 0.144 & -0.069 & -1.510 & 0.132 \\
\hline & Genotype & -0.065 & 0.031 & -0.037 & -2.075 & 0.039 \\
\hline \multirow[t]{2}{*}{ ApoA1 } & Cigarette smoking & 0.082 & 0.051 & 0.076 & 1.598 & 0.111 \\
\hline & Diastolic blood pressure & -0.003 & 0.001 & -0.125 & -2.640 & 0.009 \\
\hline \multirow[t]{5}{*}{ ApoB } & Body mass index & 0.019 & 0.003 & 0.296 & 6.758 & 0.000 \\
\hline & Glucose & 0.015 & 0.005 & 0.133 & 2.942 & 0.003 \\
\hline & Age & 0.003 & 0.001 & 0.240 & 5.153 & 0.000 \\
\hline & Cigarette smoking & -0.097 & 0.039 & -0.112 & -2.475 & 0.014 \\
\hline & Genotype & 0.003 & 0.008 & 0.007 & 0.434 & 0.000 \\
\hline \multirow[t]{2}{*}{ ApoA1/ApoB } & Body mass index & -0.046 & 0.008 & -0.274 & -6.037 & 0.000 \\
\hline & Cigarette smoking & 0.314 & 0.106 & 0.136 & 2.953 & 0.003 \\
\hline
\end{tabular}


Table VI. Continued.

\begin{tabular}{llcccrr}
\hline \multicolumn{1}{c}{ Lipid parameter factor } & B & Std. error & $\beta$ & t & P-value \\
\hline & Systolic blood pressure & -0.002 & 0.001 & -0.074 & -1.477 & 0.140 \\
& Age & -0.007 & 0.002 & -0.191 & -3.717 & 0.000 \\
Genotype & -0.019 & 0.017 & -0.017 & -1.139 & 0.000 \\
\hline
\end{tabular}

C, Mulao/male

\begin{tabular}{llccrrr}
\hline Lipid parameter & \multicolumn{1}{c}{ Risk factor } & B & Std. error & $\beta$ & P-value \\
\hline TC & Body mass index & 0.060 & 0.018 & 0.169 & 3.422 \\
TG & Waist circumference & 0.049 & 0.006 & 0.359 & 7.751 & 0.001 \\
HDL-C & Alcohol consumption & 0.100 & 0.023 & 0.203 & 4.253 & 0.000 \\
& Waist circumference & -0.013 & 0.003 & -0.234 & -4.906 & 0.749 \\
LDL-C & Age & 0.001 & 0.002 & 0.036 & 0.455 \\
ApoA1 & Body mass index & 0.043 & 0.013 & 0.156 & 3.182 \\
ApoB & Alcohol consumption & 0.116 & 0.020 & 0.280 & 5.866 \\
ApoA1/ApoB & Waist circumference & 0.009 & 0.003 & 0.127 & 0.002 \\
& Alcohol consumption & 0.130 & 0.033 & 0.190 & 2.580 & 0.010 \\
& Waist circumference & -0.016 & 0.004 & -0.208 & -4.336 \\
\hline
\end{tabular}

D, Mulao/female

\begin{tabular}{|c|c|c|c|c|c|c|}
\hline Lipid parameter & Risk factor & B & Std. error & $\beta$ & $\mathrm{t}$ & P-value \\
\hline TC & Age & 0.015 & 0.003 & 0.204 & 4.513 & 0.000 \\
\hline TG & Body mass index & 0.054 & 0.010 & 0.253 & 5.653 & 0.000 \\
\hline HDL-C & Body mass index & -0.031 & 0.006 & -0.234 & -5.206 & 0.000 \\
\hline \multirow[t]{2}{*}{ LDL-C } & Body mass index & 0.051 & 0.013 & 0.177 & 3.962 & 0.000 \\
\hline & Age & 0.012 & 0.003 & 0.196 & 4.381 & 0.000 \\
\hline \multirow[t]{3}{*}{ ApoB } & Glucose & 0.047 & 0.016 & 0.133 & 2.940 & 0.003 \\
\hline & Waist circumference & 0.012 & 0.003 & 0.192 & 4.252 & 0.000 \\
\hline & Cigarette smoking & 0.392 & 0.245 & 0.072 & 1.599 & 0.011 \\
\hline \multirow[t]{3}{*}{ ApoA1/ApoB } & Cigarette smoking & -0.602 & 0.503 & -0.055 & -1.197 & 0.232 \\
\hline & Waist circumference & -0.016 & 0.007 & -0.111 & -2.431 & 0.015 \\
\hline & Age & -0.010 & 0.003 & -0.128 & -2.793 & 0.005 \\
\hline
\end{tabular}

TC, total cholesterol; TG, triglyceride; HDL-C, high-density lipoprotein cholesterol; LDL-C, low-density lipoprotein cholesterol; ApoA1, Apolipoprotein A1; ApoB, Apolipoprotein B; ApoA1/ApoB, the ratio of Apolipoprotein A1 to Apolipoprotein B; Std. error, standard error.

environmental factors, including demographics, diet, alcohol consumption, cigarette smoking, obesity, exercise, hypertension $(14,15)$ and genetic factors, including lipid-associated gene variants, and their interactions $(16,17)$.

The Mulao ethnic group is a conservative and isolated minority. There are numerous cultural customs, including intra-ethnic marriage in this minority. The practice of arranged marriage is common, with decisions regarding future marriages often made during the individual's childhood. Divorce and remarriage are also allowed. Traditionally, females remain with their family until their first pregnancy. Prior to this, the females are often restricted from various social activities.
The wife is usually four or five years older than the husband. Engagement and marriage are socially marked with a payment from the groom to the bride's family. Notably, the preferred marriage arrangement would be the groom's maternal cousin. Therefore, it is theorized that certain hereditary characteristics and genotypes of specific lipid metabolism-associated genes in this population may be different from those in the Han ethnic group (40-42).

To the best of our knowledge, the genotypic and allelic frequencies of the ANGPTL8 rs2278426 SNP have not been reported previously in different ethnic groups. In the present study, it was observed that the frequency of the A allele was 
lower in the Han population than in the Mulao population (17.80 vs. 23.04\%; $\mathrm{P}<0.001$ ). The distribution of the GG, GA and AA genotypes was also different between the two ethnic groups $(\mathrm{P}<0.005)$, the frequencies of $\mathrm{GA}$ and AA genotypes were lower in the Han than in the Mulao groups, respectively. No significant differences were identified in the genotypic and allelic frequencies between males and females in the two ethnic groups. These results suggest that the prevalence of the ANGPTL8 rs2278426 SNP may have an ethnic preponderance.

In the current study, it was also identified that serum LDL-C, ApoA1, ApoB levels and the ApoA1/ApoB ratio in the Han group were different among the genotypes $(\mathrm{P}<0.05-0.001)$. The subjects with the GA/AA genotype had lower LDL-C and ApoB levels and higher ApoA1 levels and a higher ApoA1/ApoB ratio than the subjects with the GG genotype, but these findings were restricted to females. Serum TC, LDL-C, ApoB levels and the ApoA1/ApoB ratio in Han females, but not in males were significantly different among the genotypes $(\mathrm{P}<0.05-0.001)$, the subjects with GA/AA genotype had lower TC, LDL-C, ApoB levels and a higher ApoA1/ApoB ratio than the subjects with the GG genotype. These findings suggest that there may be an ethnic- and gender-specific association of the ANGPTL8 rs2278426 SNP and serum lipid levels.

Environmental factors, including dietary patterns, lifestyle, obesity, physical inactivity and hypertension may substantially affect serum lipid levels $(14,15)$. In the present study, it was also detected that serum lipid parameters were associated with age, gender, alcohol consumption, cigarette smoking, BMI, fasting blood glucose levels and blood pressure in the two ethnic groups. These data suggest that environmental factors also have an important role in determining serum lipid levels in the two populations. With the improvement in local living standards, the dietary intake of the Mulao population has changed gradually. However, the Mulao population generally eat cold foods and acidic and spicy dishes. Therefore soy beans and preserved vegetables are popular dietary sources. Animal offal is also commonly eaten, which has high levels of saturated fatty acids. High-fat diets, particularly those with abundant saturated fatty acids raise blood cholesterol concentrations and predispose individuals to CAD (43). Numerous studies have also stated that daily eating habits can markedly affect serum levels of ApoB, ApoA1 and their ratio, and which in turn can lead to an increased risk of CAD (44-46). In the present study, it was identified that the level of ApoB was higher in the Mulao than in the Han individual and the serum ApoA1 level was higher in the Han than in the Mulao individuals. This may be partly attributed to the difference in daily eating habits between the Mulao and Han populations.

The present study demonstrated that the genotypic and allelic frequencies of the ANGPTL8 rs2278426 SNP were different between the Mulao and Han populations. The subjects with the GA/AA genotype in the Han but not in the Mulao population had lower serum LDL-C and ApoB levels, a higher ApoA1 level and a higher ApoA1/ApoB ratio than the subjects with the GG genotype, but these results were restricted to females. Serum total TC, LDL-C, ApoB levels and the ApoA1/ApoB ratio in Han females were different among the genotypes. The subjects with the GA/AA genotype had lower TC, LDL-C, ApoB levels and a higher ApoA1/ApoB ratio than the subjects with the GG genotype. These results suggest that there may be an ethnic- and gender-specific association of the ANGPTL8 rs2278426 SNP and serum lipid levels in the populations investigated in the present study.

In conclusion, the present study detected an association of the ANGPTL8 rs2278426 SNP and numerous environmental factors with serum lipid profiles; however, there are still many environmental and genetic factors, and their interactions, that have yet to be measured. Therefore, the association of gene-gene, gene-environment, and environment-environment interactions with serum lipid levels remains to be elucidated.

\section{Acknowledgements}

The present study was supported by the National Natural Science Foundation of China (grant no. 30960130).

\section{References}

1. Greenland P, Knoll MD, Stamler J, Neaton JD, Dyer AR, Garside DB and Wilson PW: Major risk factors as antecedents of fatal and nonfatal coronary heart disease events. JAMA 290: 891-897, 2003.

2. Khot UN, Khot MB, Bajzer CT, Sapp SK, Ohman EM, Brener SJ, Ellis SG, Lincoff AM and Topol EJ: Prevalence of conventional risk factors in patients with coronary heart disease. JAMA 290: 898-904, 2003.

3. Melander O, Newton-Cheh C, Almgren P, Hedblad B, Berglund G, Engstrom G, Persson M, Smith JG, Magnusson M, Christensson A, et al: Novel and conventional biomarkers for prediction of incident cardiovascular events in the community. JAMA 302: 49-57, 2009.

4. Wang TJ, Gona P, Larson MG, Tofler GH, Levy D, Newton-Cheh C, Jacques PF, Rifai N, Selhub J, Robins SJ, et al: Multiple biomarkers for the prediction of first major cardiovascular events and death. N Engl J Med 355: 2631-2639, 2006.

5. Fernandez C, Sandin M, Sampaio JL, Almgren P, Narkiewicz K, Hoffmann M, Hedner T, Wahlstrand B, Simons K, Shevchenko A, et al: Plasma lipid composition and risk of developing cardiovascular disease. PLoS One 8: e71846, 2013.

6. Zethelius B, Berglund L, Sundström J, Ingelsson E, Basu S Larsson A, Venge P and Arnlöv J: Use of multiple biomarkers to improve the prediction of death from cardiovascular causes. N Engl J Med 358: 2107-2116, 2008.

7. Gerszten RE and Wang TJ: The search for new cardiovascular biomarkers. Nature 451: 949-952, 2008.

8. Shekelle RB, Shryock AM, Paul O, Lepper M, Stamler J, Liu S and Raynor WJ Jr: Diet, serum cholesterol and death from coronary heart disease The Western Electric Study. N Engl J Med 304: 65-70, 1981.

9. Austin MA: Plasma triglyceride as a risk factor for coronary heart disease. The epidemiologic evidence and beyond. Am J Epidemiol 129: 249-259, 1989.

10. Nissen SE, Tuzcu EM, Schoenhagen P, Crowe T, Sasiela WJ, Tsai J, Orazem J, Magorien RD, O'Shaughnessy C and Ganz P et al: Statin therapy, LDL cholesterol C-reactive protein, and coronary artery disease. N Engl J Med 352: 29-38, 2005.

11. Kwiterovich PO Jr, Coresh J, Smith HH, Bachorik PS, Derby CA and Pearson TA: Comparison of the plasma levels of apolipoproteins $\mathrm{B}$ and $\mathrm{A}-1$ and other risk factors in men and women with premature coronary artery disease. Am J Cardio 69: 1015-1021, 1992.

12. Barter P, Gotto AM, LaRosa JC, Maroni J, Szarek M, Grundy SM, Kastelein JJ, Bittner V and Fruchart JC; Treating to New Targets Investigators: HDL cholesterol, very low levels of LDL cholesterol and cardiovascular events. N Engl J Med 357: 1301-1310, 2007.

13. Teslovich TM, Musunuru K, Smith AV, Edmondson AC, Stylianou IM, Koseki M, Pirruccello JP, Ripatti S, Chasman DI, Willer CJ, et al: Biological clinical and population relevance of 95 loci for blood lipids. Nature 466: 707-713, 2010.

14. Ferber D: Lipid research. Possible new way to lower cholesterol. Science 289: 1446-1447, 2000.

15. Robinson D, Kawamura T, Hinohara S, Sakamoto Y and Takahashi T: Levels of cardiovascular risk factors in Japanese people living in the UK. J Cardiovasc Risk 2: 449-458, 1995. 
16. Ripatti S, Tikkanen E, Orho-Melander M, Havulinna AS, Silander K, Sharma A, Guiducci C, Perola M, Jula A, Sinisalo J, et al: A multilocus genetic risk score for coronary heart disease: case-control and prospective cohort analyses. Lancet 376: 1393-1400, 2010.

17. Kathiresan S, Melander O, Anevski D, Guiducci C, Burtt NP, Roos C, Hirschhorn JN, Berglund G, Hedblad B, Groop L, et al: Polymorphisms associated with cholesterol and risk of cardiovascular events. N Engl J Med 358: 1240-1249, 2008.

18. Heller DA, de Faire U,Pedersen NL, Dahlén G and McClearn GE: Genetic and environmental influences on serum lipid levels in twins. N Engl J Med 328: 1150-1156, 1993.

19. Steinmetz J, Boerwinkle E, Gueguen R, Visvikis S, Henny J and Siest G: Multivariate genetic analysis of high density lipoprotein particles. Atherosclerosis 92: 219-227, 1992.

20. Pérusse L, Rice T, Després JP, Bergeron J, Province MA, Gagnon J, Leon AS, Rao DC, Skinner JS, Wilmore JH et al: Familial resemblance of plasma lipids, lipoproteins and postheparin lipoprotein and hepatic lipases in the HERITAGE Family Study. Arterioscler Thromb Vasc Biol 17: 3263-3269, 1997.

21. Zhang R and Abou-Samra AB: Emerging roles of Lipasin as a critical lipid regulator. Biochem Biophys Res Commun 432: 401-405, 2013.

22. Musunuru K, Pirruccello JP, Do R, Peloso GM, Guiducci C, Sougnez C, Garimella KV, Fisher S, Abreu J, Barry AJ, et al: Exome sequencing Angptl3 mutations, and familial combined hypolipidemia. N Engl J Med 363: 2220-2227, 2010.

23. Wang Y, Quagliarini F, Gusarova V, Gromada J, Valenzuela DM, Cohen JC and Hobbs HH: Mice lacking ANGPTL8 (Betatrophin) manifest disrupted triglyceride metabolism without impaired glucose homeostasis. Proc Natl Acad Sci USA 110: 16109-16114, 2013

24. Quagliarini F, Wang Y, Kozlitina J, Grishin NV, Hyde R, Boerwinkle E, Valenzuela DM, Murphy AJ, Cohen JC and Hobbs HH: Atypical angiopoietin-like protein that regulates ANGPTL3. Proc Natl Acad Sci USA 109: 19751-19756, 2012.

25. Locke AE, Kahali B, Berndt SI, Justice AE, Pers TH, Day FR, Powell C, Vedantam S, Buchkovich ML, Yang J, et al: Genetic studies of body mass index yield new insights for obesity biology. Nature 518: 197-206, 2015

26. Li Q, Yin RX, Yan TT, Miao L, Cao XL, Hu XJ, Aung LH, Wu DF, Wu JZ and Lin WX: Association of the GALNT2 gene polymorphisms and several environmental factors with serum lipid levels in the Mulao and Han populations. Lipids Health Dis 10: 160, 2011.

27. Xu L, Deng QY, Li SF, Zhou LN, Gong JC and Wei BY: Genetic analysis of Mulao nationality using 15 short tandem repeats. Zhonghua Yi Xue Yi Chuan Xue Za Zhi 25: 96-100, 2008 (In Chinese)

28. Li Q, Yin RX, Wei XL, Yan TT, Aung LH, Wu DF, Wu JZ, Lin WX, Liu CW and Pan SL: ATP-binding cassette transporter G5 and G8 polymorphisms and several environmental factors with serum lipid levels. PLoS One 7: e37972, 2012.

29. Huang KK, Yin RX, Zeng XN, Huang P, Lin QZ, Wu J, Guo T, Wang W, Yang DZ and Lin WX: Association of the rs7395662 SNP in the MADD-FOLH1 and several environmental factors with serum lipid levels in the Mulao and Han populations. Int J Med Sci 10: 1537-1546, 2013.

30. Aung LH, Yin RX, Wu DF, Li Q, Yan TT, Wang YM, Li H, Wei DX, Shi YL and Yang DZ: Association of the TRIB1 tribbles homolog gene rs17321515 A>G polymorphism and serum lipid levels in the Mulao and Han populations. Lipids Health Dis 10: 230, 2011.

31. Wu DF, Yin RX, Yan TT, Aung LH, Cao XL, Miao L, Li Q, $\mathrm{Hu} \mathrm{XJ}, \mathrm{Wu}$ JZ and Liu CW: The SCARB1 rs5888 SNP and serum lipid levels in the Guangxi Mulao and Han populations. Int J Med Sci 9: 715-724, 2012.
32. No authors listed: An epidemiological study of cardiovascular and cardiopulmonary disease risk factors in four populations in the People's Republic of China. Baseline report from the P.R.C.-U.S.A. Collaborative Study. People's Republic of China - United States Cardiovascular and Cardiopulmonary Epidemiology Research Group. Circulation 85: 1083-1096, 1992.

33. Ramazauskiene V, Petkeviciene J, Klumbiene J, Kriaucioniene V and Sakytė E: Diet and serum lipids: Changes over socio-economic transition period in Lithuanian rural population. BMC Public Health 11: 447, 2011.

34. Grönroos P, Raitakari OT, Kähönen M, Hutri-Kähönen N, Juonala M, Marniemi J, Viikari J and Lehtimäki T: Relation of apolipoprotein e polymorphism to markers of early atherosclerotic changes in young adults - the Cardiovascular Risk in Young Finns Study. Circ J 72: 29-34, 2008.

35. Chalmers J, MacMahon S, Mancia G, Whitworth J, Beilin L, Hansson L, Neal B, Rodgers A, Ni C, Mhurchu T and Clark: 1999 World Health Organization-International Society of Hypertension Guidelines for the management of hypertension. Guidelines Sub-Committee of the World Health Organization. Clin Exp Hypertens 21: 1009-1060, 1999.

36. Ishii M: The sixth report of the Joint National Committee on prevention, detection, evaluation and treatment of high blood pressure, and 1999 World Health Organization-International Society of Hypertension Guidelines for the Management of Hypertension. Nihon Rinsho 58: 267-275, 2000 (In Japanese).

37. Whitworth JA, World Health Organization and International Society of Hypertension Writing Group: 2003 World Health Organization (Who)/International Society of Hypertension (ISH) statement on management of hypertension. J Hypertens 21: 1983-1992, 2003.

38. Yu ZB, Han S, Chu J, Xu Z, Zhu C and Guo X: Trends in overweight and obesity among children and adolescents in China from 1981 to 2010: A meta-analysis. PLoS One 7: e51949, 2012.

39. Müller MJ, Lagerpusch M, Enderle J, Schautz B, Heller M and Bosy-Westphal A: Beyond the body mass index: tracking body composition in the pathogenesis of obesity and the metabolic syndrome. Obes Rev 13: 6-13, 2012

40. Liu C, Liu C and Wang H: Genetic Diversity at 15 STR loci in two tribal populations in Southern China. Forensic Sci Int 162: 28-32, 2006.

41. Deng Q, Xu L, Gong J, Zhou L, Li S, Deng X, Luo G and Xie X: Genetic relationships among four minorities in Guangxi revealed by analysis of 15 STRs. J Genet Genomics 34: 1072-1079, 2007.

42. Yan YX, Dong J, Wu LJ, Shao S, Zhang J, Zhang L, Wang W, He Y and Liu YQ: Associations between polymorphisms in the glucocorticoid-receptor gene and cardiovascular risk factors in a Chinese population. J Epidemiol 23: 389-395, 2013.

43. Salonen JT, Salonen R, Penttila I, Herranen J, Jauhiainen M, Kantola M, Lappetelainen R, Maenpaa PH, Alfthan G and Puska P: Serum fatty acids, apolipoproteins, selenium and vitamin antioxidants and the risk of death from coronary artery disease. Am J Cardiol 56: 226-231, 1985.

44. Solá R, Fitó M, Estruch R, Salas-Salvadó J, Corella D, de La Torre R, Muñoz MA, López-Sabater Mdel C, Martínez-González MA, Arós F, et al: Effect of a traditional Mediterranean diet on apolipoproteins B A-I and their ratio: A randomized controlled trial. Atherosclerosis 218: 174-180, 2011.

45. He Y: Serum Apolipoprotein AI, B Levels in patients with coronary diseases. Zhonghua Xin Xue Guan Bing Za Zhi 18 217-219, 1990 (In Chinese).

46. Winocour PH, Durrington PN, Bhatnagar D, Mbewu AD, Ishola M, Mackness M and Arrol S: A cross-sectional evaluation of cardiovascular risk factors in coronary heart disease associated with type 1 (insulin-dependent) diabetes mellitus. Diabetes Res Clin Pract 18: 173-184, 1992. 